\title{
Internet governance as joint effort. (Re)Ordering search engines at the intersection of global and local cultures
}

\author{
Astrid Mager \\ Austrian Academy of Sciences - Institute of Technology Assessment, Austria
}

This is a preprint version of an article published in New Media \& Society. It may include slight differences to the published version.

Please cite the published version as follows:

Mager, A (2018) Internet governance as joint effort: (Re)ordering search engines at the intersection of global and local cultures, New Media \& Society, article first published online: February 18, 2018: https://doi.org/10.1177/1461444818757204

The preprint version can be accessed here:

http://epub.oeaw.ac.at/ita/ita-papers/internet-governance-as-joint-effort.pdf

\begin{abstract}
In this article, I investigate internet governance in practice by focusing on search engines, Google in particular. Building on STS-grounded internet governance research, I ask how different stakeholders interpret governing by algorithms, the governing of algorithms, and the limits of various governing modes when considering local specificities. To answer these questions, I conducted 18 qualitative interviews with key experts involved in search engine governance from four distinct societal domains: policy, law, civil society and the IT sector (from Austria and/ or the European level). In this analysis, I show that perceptions of search engine governance are shaped in specific cultural contexts, but also within particular social groups and their situated knowledges. I further elaborate how joint efforts are imagined as a means to challenge powerful search engines and their governing abilities cutting through different societal arenas and areas of expertise. Finally, I discuss implications of this analysis regarding the complex relationship between global technology and local cultures.
\end{abstract}

Keywords: internet governance, search engine, qualitative interviews, Austria, European Union, science and technology studies, governing by algorithms, governing of algorithms, situated knowledges

\section{Correspondence:}

Astrid Mager, Austrian Academy of Sciences (ÖAW) - Institute of Technology Assessment (ITA), Apostelgasse 23, 1030 Wien, Austria

Email: astrid.mager@oeaw.ac.at, Twitter: @astridmager 


\section{Introduction}

Internet technology companies have grown into powerful actors who intervene in world politics in various ways. Just recently, after Donald Trump announced a ban on visitors from seven predominantly Muslim countries (January 2017), a coalition of large and small technology companies - including Google, Apple, Facebook, Twitter and Microsoft - filed a legal brief against Trump's travel ban. "Silicon Valley is stepping up", as Sam Altman from the startup funder Y Combinator commented in the New York Timesi. Around the same time, rumors started to spread that Facebook's Mark Zuckerberg is himself considering running for the US presidencyii. Not to speak of all the discussions in academic circles on how search engines may have helped Donald Trump to become president in the first place iii or how social media may have influenced the UK's "Brexit"

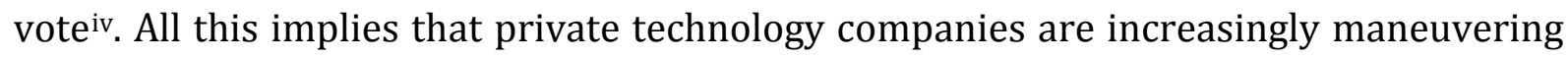
on political terrain. In fact, political leaders from different countries have started to negotiate with Silicon Valley companies on their own. Their overlying goal is to benefit from the vast amount of data these big players are sitting on, usually under the pretext of terror prevention strategies. This indicates that the influence of transnational technology companies reaches far beyond the geographical borders of the USA. Rather, it intersects with national policy strategies and local socio-political cultures.

While IT companies are increasingly operating on classical political territories, at the same time, they are introducing new forms of politics on technological grounds. Instead of explicit rules and regulations, technological forms of politics are shaped by protocols and sociotechnical arrangements. DeNardis (2009) speaks of "protocol politics" as a way of characterizing this kind of governance that is co-produced by technological and political means. Rather than elected, flesh-and-blood politicians, an assemblage of social choices and technical entities including code, software and technical infrastructure define the rules of this game. Accordingly, the field of internet governance (IG) has grown significantly in recent years. While IG scholars traditionally investigate how international organizations and multistakeholder arrangements govern internet technology (e.g. Levinson and Marzuki 2015, 2016), scholars in the field of science and technology studies (STS) have started to focus on protocols and practices. They have shown how algorithms, lines of code, bits and pieces of software as well as hardware components contribute to internet governance (Gillespie 2014; Musiani 2013a, 2013b; Ziewitz 2016, Ziewitz and Pentzold 2014). Moreover, they have investigated how corporate interests are inscribed in technical components and act through their technical Gestalt (DeNardis 2009, 2014; Katzenbach 2013; Mager 2012a). They conclude that internet governance not only takes place in global institutions, but also through day-to-day interactions with technology, in "mundane activities" (Hofmann et al. 2017: 1415).

Drawing on this body of work, in this paper I investigate internet governance in practice by specifically focusing on search engines. Musiani (2013a) and Saurwein et al. (2015) distinguish between two types of governance in regard to search engines and ranking systems: "governance by algorithms" and the "governance of algorithms". The first type 
relates to the governing power of algorithms themselves or the "power through the algorithm" (Beer 2009). The second type captures classical forms of governance, "the governance of algorithms, the extent to which political regulation can affect the functioning of the instructions and procedures subtending technology" (Musiani 2013a: 2). These two types of algorithmic governance conceptually guide my analysis in the context of search engines. These are the central research questions: What challenges do different types of actors identify regarding governing by algorithms? What solutions do they suggest in terms of the governing of algorithms? Where do they see limits of the various governing modes, considering local specifics? To answer these questions, I have conducted 18 qualitative interviews with key actors involved in search engine governance stemming from four distinct societal domains: policy, law, civil society and the IT sector. All actors work in the area of Austrian and/ or European search engine policy. Austria is a country with a long tradition in data protection and a rather restrained technology policy (Felt 2015), as further described below. Googlev is at the center of discussions in this study since it holds a quasi-monopoly position in Europe of more than $90 \%$ (Jacobsen 2016) and poses crucial questions in terms of internet governance.

In the following pages, I discuss how internet governance (IG) research and science and technology studies (STS) have co-emerged in recent years. Within the context of STSgrounded IG research, I then elaborate on global search engine governance and its relation to local specificities, both in terms of "geographical arrangements" (Law 2008: 1) and "situated knowledges" (Haraway 1988). After a description of the empirical study and methods used, I present the analysis in three sections, focusing on different perceptions of: 1) governing by algorithms, 2) the governing of algorithms and 3) limits of governing modes rooted in local cultures. To conclude, I discuss the implications of this analysis in regard to the complex relationship between global technology and local cultures.

\section{IG research meets STS}

The term internet governance has been constructed and deconstructed multiple times in recent years. Van Eeten and Mueller (2012) argue that the field labelling itself as IG research only captures a narrow field of study, primarily focusing on transnational institutions like the "Internet Governance Forum" (IGF) or the "Internet Corporation for Assigned Names and Numbers" (ICANN). The authors thus conclude: "There is a remarkable absence of governance in what is commonly called Internet governance" (Van Eeten and Mueller 2012: 728). To broaden this narrow concept of internet governance, STS scholars have suggested investigating IG in practice. Rather than providing yet another IG definition, they propose to investigate how IG figures in internet architecture, sociotechnical practices and private modes of ordering (DeNardis 2009, 2014; Musiani 2015; Ziewitz 2016; Ziewitz and Pentzold 2014).

DeNardis $(2009,2014)$ has analyzed technical infrastructures as arrangements of power and politics, negotiations over internet architecture as conflicts of norms, values and 
rights, and internet governance as increasingly privatized endeavor enacted by corporations and non-governmental bodies. Katzenbach (2013) argues that technological devices and internet services should not be seen as external triggers for regulation, but as parts of the heterogeneous networks that constitute the social, just like norms or power. He uses the notion of "private ordering" to capture how mechanisms of private law, including contracts, licenses and end-user agreements increasingly complement, and even undermine, traditional mechanisms of public law, especially concerning copyright and privacy issues (Katzenbach 2013: 402). Compared to governance, the notion of "ordering" focuses on practices and procedures rather than formalized institutions and regulations, which makes it a useful tool for STS-oriented IG research. Ziewitz and Pentzold (2014) refer to Law's (1994) concept of ordering to analyze how IG is enacted and performed in different contexts. They aim to multiply the notion of internet governance by showing that different versions of reality relate to different "modes of ordering" (Ziewitz and Pentzold 2014: 2008). To illustrate their argument, the authors discuss five versions of the "Twitter Joke Trial", an internetrelated conflict in Great Britainvi. In this analysis, they show how different readings of the "Twitter Joke Trial" invoke different solutions to the problem. Reading the Twitter message of blowing up a British airport as a joke, a terror threat or a case of user surveillance leads to very different proposals for policy actions, such as intervening in Twitter's self-governance, closing a regulatory gap, or developing security-conscious social media use. These examples illustrate the interdependence of different versions of reality and visions of governance, an aspect I will explore further in my analysis.

Hofmann et al. (2017) suggest grounding internet governance in mundane practices of coordination. They explain that "grounding governance in coordination means studying ordering processes from the bottom-up rather than proceeding from regulatory structures" (Hofmann et al. 2017: 8). The authors then argue that mundane activities of coordination become reflexive when ordinary interactions break down and become problematic. Drawing on Boltanski and Thévenot (2006) they call such moments "critical moments". In critical moments, actors begin to redefine the situation in question since routines are challenged, contested and displaced through acts of articulation and justification. The authors conclude that “'critical moments' open temporary windows to the precarious conditions underpinning social coordination, which, more often than not, may be in need of adaption" (Hofmann et al. 2017: 14). In view of my empirical material, Edward Snowden's intelligence leaks of the massive surveillance performed by secret services and internet companies may be interpreted as such a critical moment. An Austrian activist from my interview sample referred to Snowden's revelations by dubbing it "the Chernobyl of data protection". Having conducted my study one year after the Snowden disclosures, the dust has started to settle and different social actors have had some time to reflect on mundane practices of coordination and modes of adaption. To lay the ground for the empirical analysis, I will now discuss the particularities of global search engine governance and its relation to local cultures. 


\section{Global search engine governance and local specificities}

Critical internet researchers have pointed to various modes of governing performed by globally operating search engines. First of all, search engines are discussed in terms of their central role in ordering web information. Introna and Nissenbaum (2000) were amongst the first scholars having pointed to the political qualities of search engine algorithms. According to them, these are rooted in mechanisms of determining systematic inclusions and exclusions and factors leading to systematic prominence for some sites and systematic invisibility for others (Introna and Nissenbaum 2000: 171). The authors consider the influences that come into play in these ways of ordering political because they strongly shape what people find and select. Their arguments are empirically confirmed by studies having shown how people search for, select and engage with online information (Seale 2005, Goel et al. 2010, Mager 2009, 2012). Introna and Nissenbaum hence conclude that search engines' ways of functioning, especially corporate ones that are largely black boxed, run counter the ideology of the Web as a public good. In a similar vein, Beer (2009) argues that, unlike hegemonic power operating from the outside, power is now working from the inside. Following Lash's (2007) notion of post-hegemonic power, Beer (2009: 999) elaborates that there is a complex "underweave of power at play in the digital mundane". Following these arguments political qualities and biases can be found in all search engines and ranking mechanisms, as White and Horwitz (2009) have shown in the medical context, for example. Since Google constitutes such a powerful source of access in wide parts of the world, however, the "'inherently political" qualities" (Musiani 2013b: 5) of Google are particularly discussed. In reference to Wu (2010) Musiani (2013a: 4) argues that Google, "as the "master switch" of the internet (Wu 2010: 279-280), centralises and organises the circulation of information in the network of networks, and for every search interrogation and request, arbitrates on what's important and relevant".

Secondly, corporate search engines have been described as governing by shaping users' behavior. Badouard et al. (2016: 3ff) elaborate how Google governs by "directing" users' behavior. Drawing on Foucault's (1982) notion of governmentality and discussing Google's Webmaster Tools, the authors explain how Google directs publishers' actions by installing an incentive-oriented governmentality regime. They argue that Google encourages website publishers "to produce their content in a certain way by giving advice on the best way to make and publish content, if they want to be visible on the leading search engine." (Badouard et al. 2016: 4). Moreover, they argue that designing a website, content management system or social network (e.g. Google+) can be interpreted as an act of making users adopt a certain behavior, while developing a mobile operating system (e.g. Google's Android) can be seen as an act of framing what can and cannot be done with a mobile phone. The authors thus argue that this new means of exerting power is about influencing other people's behaviors (Badouard et al. 2016: 2). More fundamentally, Cohen (2012) argues that networked information technologies reconfigure the self as such: 
The social and cultural patterns that mediate the activities of self-constitution are being reconfigured by the pervasive adoption of technical protocols and services that manage the activities of content delivery, search, and social interaction. (Cohen 2012: 130)

This reconfiguration of the self happens within a larger techno-political climate that Cohen (2014) labels the "surveillance-innovation complex". In this paradigm, user surveillance is seen as a necessary prerequisite for innovation, while privacy is framed as "antiprogressive, overly costly, and inimical to the welfare of the body politic" (Cohen 2013: 1904). The author concludes that corporate information technologies, and the neoliberal rhetoric surrounding them, redefine the very nature of the self, surveillance and privacy, which triggers crucial regulatory effects, an aspect that will be discussed in my analysis.

Finally, private modes of ordering performed by corporate search engines like Google have also been discussed (DeNardis 2009, 2014; Katzenbach 2013). Belli and Venturini (2016) argue that contractual agreements like terms of service can be directly implemented through technical means like algorithms, online platforms, or internet traffic management techniques. These agreements

may be considered as a kind of private law-making system, because the substantive provisions set in the agreements - which may apply transnationally - regulate the relationships between the parties with a binding force that may be analogue to or even stronger than the one exercised by law (Shapiro 1993, quoted in Belli and Venturini 2016: 2).

Given the great number and variety of Google services, its power to govern by private ordering has been discussed, particularly in regard to commodification, privacy and surveillance (Fuchs 2011). In reference to Hardt and Negri (2000) Google is described as having established a "technological empire" (Pasquinelli 2009: 158). Miller (2004: 81) argues that the rules of this "imperial machine" are not only written in the political arena, but also in scientific and engineering laboratories. Mager (2017) exemplifies how global IT companies expand "technological zones" (Barry 2006) transgressing national boundaries and challenging cultural specificities and political territories on the ground. In the "surveillance-innovation complex" users are primarily constructed as consumers and regulation is mainly directed at forms of private law-making and industry selfregulation, which are understood as fostering innovation (Cohen 2014: 8). This poses crucial challenges for European data protection regulators attempting "to maintain a generally precautionary stance towards personal data protection" (Cohen 2016: 394) that is supposed to protect citizens and their rights. This indicates that notions like privacy and data protection are culturally shaped and hence tied to particular localities and their economic and socio-political characteristics (Cohen 2013; Mager 2017). But how can "the local" be grasped analytically in relation to global technology? 
STS has a long tradition of showing how local specificities shape the development and governance of global technology. Martello and Jasanoff (2004) explicitly address the importance of the local in the context of global environmental governance. They argue that local knowledge and identities are of growing importance in global governance and challenge "the simplifying and universalizing forces of global science, technology, and capital" (Martello and Jasanoff 2004: 4). Both the local and the global should not be seen as fixed or rigid entities, rather as being constantly made and remade in processes and practices. They are "constituted through the beliefs, actions, and normative commitments of relevant social actors" (Martello and Jasanoff 2004: 16). These actions and beliefs are at the heart of my study. In the analysis, however, the local not only refers to the cultural specificities of Austria, but also to individual practices and perspectives. Martello and Jasanoff (2004: 17) suggest that the local may also be found in how users understand a technological system, for example. This interpretation of the local relates to Haraway's (1988) concept of "situated knowledges". Following a constructionist argument, Haraway (1988) argues that all forms or knowledge claims, including scientific ones, are socially constructed and made. "I am arguing for politics and epistemologies of location, positioning, and situating, where partiality and not universality is the condition of being heard to make rational knowledge claims." (Haraway 1988: 589)

\section{Study and methods}

To investigate how search engine governance figures in local practices, I focus on the Austrian context. Austria is a country with a long tradition of data protection. It was one of the first countries in Europe to lay down data protection as a fundamental right in its Constitution in 1978 (Souhrada-Kirchmayer 2010). Its strong attitude towards data protection may be seen in several occasions. In 2010, Austria opposed Google's Street View service on the basis of privacy violations (along with Germany and the Czech Republic) vii. After Google's illegal scraping of open WiFi data, Austria's data protection commission banned Street View in May 2010. One year later, the ban was lifted, but Google was required to provide Austrians with the option to blur out their homes. Consequently, Google dropped the mapping for most of the country. In Hofmann et al.'s (2017) terms Austria may thus be seen as having had its "critical moment" long before Edward Snowden pushed corporate surveillance into the spotlight in June 2013. Its moment culminated in an event where a farmer attacked a Google vehicle with a pickaxe, an incident widely covered in the Austrian mass media (Mager 2017). Austria's strong data protection-friendly stance may also be seen in negotiations regarding the EU data protection reform that started in 2012. Austrian representatives took an active role in fighting for strong data protection standards in both the European Parliament and the Council of Ministers. It is interesting to note that the rhetoric of small Austria against large corporations can be traced back to narratives related to other technologies, most importantly agricultural biotechnology (Felt 2015; Torgersen 2002). The question remains, however, whether this restrained technology policy is ubiquitous within the cultural context of Austria or whether different perceptions of technology, and related 
modes of governance, may be identified when taking different situated perspectives into account.

To answer this question, I conducted 18 qualitative interviews with key actors involved in search engine governance from the realms of policy, law, civil society and the IT sector: 1) five policy makers: two Austrian members of the European Parliament (MEPs), one employee of the European commission, one member of the Austrian parliament, and one representative from the Austrian consumer protection agency viii, 2) four legal experts: one legislator having contributed to the EU data protection reform, one representative from the Austrian data protection authority, and two lawyers specialized in data protection, 3) six representatives from civil society: three individual activists (all of them working on the Austrian and the European level) and three members of organized groups (one from a European advocacy group defending rights and freedoms online headquartered in Brussels, one from an Austrian NGO concerned with EU law enforcement, and one from an Austrian advocacy group for fundamental rights, and 4) three IT professionals: one computer scientist and two stakeholders from the IT industry (one from an organization lobbying for the Austrian internet economy and one from Google Switzerland representing Austria). All interviewees may be considered key actors in their respective fields according to the high positions in their institutions and the high recognition of their expertise in media and policy circles. 16 interviews were conducted face-to-face, two via Skype.

Given the interviewees' important positions in the respective issue areas, the interview method chosen was the expert interview. More specifically, the theory-generating expert interview because it corresponds well to my research purpose of understanding local interpretations of global search engine governance. Bogner and Menz (2009) ground this interview method in the sociology of knowledge, which understands social reality as being constructed by acts of interpretation. "In theory-generating expert interviews, we consult experts because their action orientations, knowledge and assessments decisively structure, or help to structure, the conditions of action of other actors, thereby showing that expert knowledge has a socially relevant dimension." (Bogner and Menz 2009: 54) The authors further argue that an expert should be perceived as having technical, process and interpretative knowledge referring to a specific field of action.

In line with the methodology of expert interviews, my interviewees were chosen following the technique of theoretical sampling, which enables the researcher to select interviewees one after another and develop a theory that is grounded in data. Following this Grounded Theory approach (Glaser and Strauss 1968), I started by conducting interviews with well-known experts in the respective fields and then moved on to actors recommended in the first round of interviews ${ }^{\mathrm{ix}}$. All interviews were conducted between July 2014 and October 2014, one year after the Snowden revelations. To be able to cross-analyze the interviews, a rough interview guideline was used. The first cluster of questions focused on perceived challenges regarding general search engines, Google in particular. The second set of questions focused on suggested solutions to the problems. In this context, the EU data protection reform was mentioned regularly since it was in 
full swing during the time the interviews were conductedx. Additionally, the "right to be forgotten" judgment of the European Court of Justice (ECJ) was discussed since it was a recent case at the time. In 2014, the ECJ forced Google to delete illegal or inappropriate information about a person from the Google index if the person concerned requests it (at least from its European databases) ${ }^{\mathrm{xi}}$. Finally, questions about the governing ability of nation states and local entities were posed to gain further insights into the specific cultural context of Austria. Local aspects, however, were discussed throughout the interviews since not only "geographical arrangements" (Law 2008: 1), but also "situated knowledges" (Haraway 1988) were of interest to me.

\section{Empirical analysis: IG as joint effort}

The empirical analysis is presented in three parts following the conceptual questions introduced before. They will focus on 1) perceived challenges having to do with governing by algorithms, 2) suggested governing modes of algorithms and, 3) the limits of different forms of governance rooted in local specificities.

\section{Governing by algorithms}

Revisiting search engines' different modes of governing by algorithms (Musiani 2013a; Saurwein et al. 2015), private modes of ordering were prominently mentioned in the interviews, especially techniques of user profiling. How Google's "power through the algorithm" (Beer 2009) was interpreted depended on the respective viewpoints however.

Representatives from the policy realm framed the issue in terms of democracy. In addition to critically discussing techniques of user profiling and commodification, they expressed an overall concern with Google's dominant role in society, which they saw as threatening democracy at large. An Austrian member of the European Parliament (MEP) sketched the picture in rough patterns:

I think Google is going to be an exterritorial agency shaping future developments without any democratic legitimacy, without any accountability to citizens. Google is a driver not only for technological and economic developments, but also a driver for societal developments triggering new forms of human behavior. There will be new forms of life someday. And all this happens without any societal consensus. This is what bothers me. ${ }^{x i i}$

This quote illustrates the deep impact the company is expected to have on society. The Austrian politician spoke about Google's central task of providing access to knowledge, which she described as a "question of power". Talking about the non-transparent character of Google's search algorithm, terms of service, and business model, the consumer advocate said that Google has the "power to autonomously determine things regardless of anything and anyone." All these quotes indicate that stakeholders from the policy realm described Google's governing abilities in terms of power politics. Having 
become the "master switch" (Wu 2010; Musiani 2013a) of the internet, Google was interpreted as being in charge of "basic infrastructure" (MEP) without having any political legitimacy. Instead of seeing Google as "directing" (Badouard et al. 2016: 3ff) specific user behavior, they portrayed Google as autonomously defining socio-political developments and transforming society as a whole, which resembles Cohen's (2012) work on reconfigurations of the self due to networked technologies.

While policy makers interpreted Google as having escaped political decision-making processes, legal experts portrayed Google as a "rule-maker" rather than a "rule-taker" (Marsden 2011: 99). One example given for ignoring European rules and regulations was Google's strategy of writing non-transparent terms of service perceived as invalid according to European consumer protection law. Another example mentioned in the interviews was Google's technique of user profiling, which was interpreted as being conducted "without any legal basis" (legal expert). A lawyer specialized in data protection added that Google would transform the legal concept of personal data itself: "It is a misunderstanding that one thinks that data is only relevant for data protection if it contains name and address. These companies don't care about that." Drawing an analogy to state surveillance, the legislator involved in the EU data protection reform said:

(...) if I count these profiles as personal data, which is not entirely clear, Google would create a comprehensive collection of characteristics, which can be attributed to a person, without precedent in the whole of history. State administration has a lot of data, but is not allowed to merge them. The state is not allowed to build a profile containing all activities related to a single citizen. This is not allowed and now the interesting question arises: What does it mean if a private company does it for the first time in history?

In this quote, Google is seen as subtly taking over tasks and responsibilities that had resided with public institutions in former times. Moreover, Google was interpreted as "making" (Marsden 2011: 99) law by technically introducing rules and regulations. Having heard a data protection officer from Google speaking at a conference, a lawyer remembered him saying: "You know, there is a global data protection standard: ours. (...) Why would I need to contribute to an initiative, if I already created the data protection standard in fact?" The interviewee's story indicates that the company was perceived as setting standards on its own rather than contributing to institutional standard-setting procedures.

Civil society actors were concerned about Google's governing abilities in more practical terms. The issue of "indirect personal data" (member of the European advocacy group), for example, was explained in this way: "This is no legal problem, this is a problem of proof" (member of law enforcement NGO). The activist went on with a wink: "because they say: prove to me that we can calculate who you are on the basis of data that is on 
our server, which we don't give you". The controversy around this new type of personal data is a good example of the interviewees' perception of Silicon Valley companies intervening in traditional governance processes, while, at the same time, introducing new forms of governance on technological grounds. Their volatile character was seen as helping them to transgress geographical borders and political territories. The activist from the enforcement NGO coined the notion "virtual multinational companies" to pin down their distinct character compared to powerful firms of the past like Shell:

And there is the additional problem that these companies are virtual, which means that they can change their state of business any time, at least on paper, because everything is in the cloud. There is no physical location anymore. And that makes them more flexible than the old multinational companies because they had to put their oil platforms somewhere, their refineries, and their petrol stations to sell their oil and so forth. There was some local relation at least, where something could have been done. And now the point has come where governments look pretty stupid.

Terms like "imperialistic", "monopolistic" or "authoritarian, paternalistic zombie company" (all individual activists) further suggested that activists tended to support the argument of Google having created its own "technological empire" (Pasquinelli 2009: 158), leaving behind traditional forms of governance linked to public institutions and political territories.

Finally, stakeholders from the IT sector shaped Google's algorithmic modes of governing as techno-political issues. While the computer scientist was mainly concerned about the concentration of internet services and their non-transparent algorithms due to their corporate nature, the lobbyist from the Austrian IT economy identified "the problem" as being on the side of policy rather than industry: "Politics is facing the internet totally incompetently." Sharing this perception, the Google employee picked up the "right to be forgotten" case to illustrate the incompetence of policy and legislation from the company's viewpoint:

This is an attack on the freedom of expression. This was our position in a nutshell. It is tricky if you start intervening in search results because it is always a balancing act between the right to privacy, the right to be forgotten, and the right to access to knowledge and, yes, freedom of expression. But then the ECJ decided otherwise, against us. We were not happy about it, but within two weeks, I think, the company managed to create the online form, organize the processes, hire lawyers. It is no automated process. There are lawyers deciding on each case. We were turned into assistant judges, which we do not like. We have argued against that, but we are aware of the responsibility now.

The notion "assistant judge" indicates that Google perceived itself as having been pushed 
into societal tasks without necessarily wanting them. Later in the interview, the Google employee added that European legislation would be mainly directed against companies like Google, which are used as "scapegoats" since there is no way to bring a case against the US government itself. The geopolitics that plays into the matter is discussed below.

All these examples show that Google was interpreted as a powerful actor privately fulfilling tasks and responsibilities of public concern. Moreover, it was described as introducing new forms of governance on technological grounds, transgressing geographical boundaries and political terrains. Whether these developments were interpreted as a threat to democracy, as an act of rule-making, as a practical dilemma, or as a techno-political problem depended on the respective viewpoints. If and how these different versions of reality were coupled with different perceptions of the "governing of algorithms" (Musiani 2013a; Saurwein et al. 2015) is discussed in the next section.

\section{Governing of algorithms}

Corresponding to their perceived loss of control, policy makers expressed the need for "regaining political sovereignty" (MEP) over sociotechnical developments. The consumer advocate said: "the European commission has to get active. Who else would have enough power of negotiation to challenge these internet companies?" Later in the interview, she mentioned law enforcement as another necessary condition for regaining control: "you can watch some time how things are not resolved (...) but for the sake of the rules of law it would be important to build up expertise on how to enforce law despite all hindrances." The Austrian politician suggested a more fundamental solution to the problem. Drawing an analogy to feminist politics, the interviewee explained that net politics should not only be understood as a matter of privacy or Google Street View projects, but as a matter of fundamental rights, in the way that feminist politics is not only about female suffrage. One step towards reformulating net politics, she suggested, would be (re)conceptualizing the parliament as the "highest democratic realm of negotiation". Saying the parliament is currently "a house for guiding through lobby interests", she concluded, "and there it gets lost, the importance of reformulating human rights in net politics." This narrative closely relates to the search engine imaginary shaped in European policy discourses that conceptualize fundamental rights as core European values (Mager 2017).

Legal experts perceived regulation and law enforcement as the most appropriate tools to force transnational technology companies to "take" (Marsden 2011: 99) European law. Having been asked who he thinks would be responsible for solving problems posed by corporate search engines, the legislator answered straight away: "In my view, it's the responsibility of the regulators of course, that is governments in combination with parliaments and legislation. It is the task of the state, who else should do it?" A lawyer labeled the EU data protection reform as a great sign of "progress" in this respect. 
Corresponding to the expressed concerns regarding user profiling, he added: "The positive aspect of the new EU regulation is that the so-called user profiling is supposed to be highly protected. Profiling will only be permitted if the person explicitly approves." Lawsuits, courts and high sanctions were further mentioned as necessary requirements for making IT companies play by the rules. The "right to be forgotten" case, which was strongly criticized by the Google employee, was perceived as "groundbreaking" (lawyer) because the ECJ clarified that Google has to obey European law. Accordingly, both the representative of the Austrian data protection authority and the employee of the European commission (EC) considered courts to be central actors forcing companies like Google to obey European law. Referring to the long negotiations for the EU data protection reform, the EC employee concluded: "If politics sleeps, then the court steps in."

Civil society actors mentioned data protection agencies as important actors in the practical enforcement of European law. To be able to successfully sanction Silicon Valley companies, however, they would need to be better equipped with "technical expertise" (member of the European advocacy group). Talking about how Google is "manipulating" (individual activist) user behavior, civil society actors also mentioned digital literacy as a central driver of change. Having been asked how society can handle the challenges Google poses, the activist from the fundamental rights advocacy group said straight away, "I think the very first step is raising critical awareness. Everything else, including data protection initiatives and lawsuits, has to be carried out as well, but the very first step is education and digital literacy." Besides educational institutions, civil society was seen as responsible for raising awareness in the population. In addition, a service agency was imagined to be able to practically help citizens fighting for their rights since "what we need is creating facts by citizens. This is what is totally lacking" (activist from the law enforcement NGO). Giving justice to the technical complexity of the matter, a technical solution was finally envisioned as a way out of the dilemma: "Privacy by design, (...) privacy by default, privacy-enhanced technologies and so forth. This is where the journey should go, where research should be directed" (activist from the rights advocacy group). Especially in the aftermath of the NSA affair, "post-Snowden products" (individual activist) were seen as having a great potential for success. In this narrative, culturally shaped notions of privacy coupled with strong European data protection standards were interpreted as a business advantage for the local IT industry, a viewpoint challenged by the IT professionals, as we will see below.

According to the perceived techno-political problem, IT professionals proposed technologically (re)defining the rules of the game. The computer scientist proposed open standards as a way of allowing users to integrate accounts, contacts and data from different platforms and services. In this narrative, hackers were seen as responsible drivers for reshaping technology: "Many technologies may be seen as wild horses and it's the hackers who tame them for our purposes" (computer scientist). The Google employee picked up the discourse of open standards, too, claiming that the company would allow users to export data from various accounts and integrate it in new services. 
However, contrary to the computer scientist who imagined "better ways of managing the commons", the Google collaborator envisioned a market solution. Referring to the American saying of the competition being "only one click away" he said:

If we lose user trust, then we're right out of it, this is our strongest regulator after all. You don't even have to speak of self-regulation, this is our business case. If we lose the confidence of our users then we're gone from one day to the next, to overstate a bit.

Corresponding to the perception of policy makers being incompetent, a market solution was framed as being the most appropriate mode of governing in the eyes of the Google employee. In contrast, classical modes of governance were seen as running the risk of endangering innovation and IT economies. In this rationale, the role of policymaking was reduced to providing broad "crash barriers" instead of "detailed regulations" (Google employee). These quotes can be seen as reproducing, and reinforcing, the rhetoric of privacy regulation as hindering innovation, which is part of the wider context of the neoliberal "surveillance-innovation complex" (Cohen 2014).

Coupled with different versions of Google's governing abilities, different visions regarding the governing of algorithms were imagined, ranging from regaining political sovereignty over sociotechnical developments, forcing IT companies to take European law, empowering users and encoding public values in technology, to autonomous modes of (re)engineering society by technological and economic means. Since corporate surveillance was largely interpreted as a threat to privacy - a widespread interpretation, but by far not the only one (Lyon 2002) - regulation and law enforcement were still strongly counted on. Actor groups, having pointed to the increasingly mundane character of surveillance, additionally imagined modes of governance located in user practices, business models and technology itself. Where the limits of these different governing modes lie is finally discussed by focusing on "geographical arrangements" (Law 2008: 1) and "situated knowledges" (Haraway 1988).

\section{3) Local perspectives}

Since representatives from all social groups articulated their preferred "modes of ordering" (Ziewitz and Pentzold 2014), the question remains as to why things have not yet been resolved. Looking at the geopolitical dimension of search engine governance from local perspectives enables us to better understand the complexity of the matter.

When talking about specific ways of regaining political sovereignty over global search technology, policy makers framed cultural differences as complicating these processes. Talking about the EU data protection reform, for example, my interviewees identified different perceptions of privacy, each of which is deeply rooted in different historical 
events, as major obstacles to common data protection standards:

The way of looking at privacy issues is fundamentally different in the US. USAmericans did not have traumatic experiences with a derailed state. Fascism, surveillance states, the former East Germany and so forth. The experience of what a derailed state can do with a data set does not exist in the US. This is the reason why debates about data protection standards are heated and shaped by misunderstandings on either side of the Atlantic." (MEP)

Cultural differences, however, were not only identified "on either side of the Atlantic", but also within the boundaries of the EU. From the Austrian perspective, countries like Great Britain, which was still part of the EU during the negotiation process, and Ireland were characterized as "blocking" (MEP) the reform process, while countries like Germany and Austria were described as privacy-friendly, supporting strong data protection standards. Finally, discrepancies within Austrian net politics were mentioned as yet another reason for the lack of a "consolidated position" (consumer advocate). To overcome cultural discrepancies and strengthen local voices in global search engine governance, a joint effort was called for, both within and beyond the policy arena. The European policy community was invited to put aside "particular interests" (consumer advocate) and to develop "a strong data protection standard acknowledging our historical experiences in Europe" (MEP). The other EP member reached beyond the policy realm and encouraged civil society actors to share their technical know-how and expertise to help make policy makers less vulnerable to industry lobbying. These narratives already hint at a strategy shared by all four actor groups: the strategy of drawing other actors into the picture once the limits of their own governing abilities were reached.

Legal experts referred to "massive lobbying" (lawyer), by both the IT industry and governments, as having prolonged the EU data protection reform. According to the EC employee, this shows that there is a law to be made "that decides how Europe will position itself towards mass processing of personal data and information". This quote indicates the geopolitical dimension of the issue at stake. The reform process was not only framed as an act of lawmaking, but also as a way of "positioning" Europe in relation to data processing and the information economy more generally. As a lawyer put it bluntly:

Well, this means that I have read in the newspaper once that Angela Merkel received a message from the US Department of Justice saying that if she consents to the draft of the data protection reform, German companies will have to pay for it. What should Angela Merkel do? She can answer by saying "I don't care" and she will have to take criticism from the German industry or she can answer by saying "I do care" and will have to give in somewhere. (...) And because the US economy is important and powerful, of course, the threat of punishing the German economy has to be taken seriously. This is a purely political question. 
This quote refers to the "privatization of internet governance" (DeNardis 2010), not only in terms of algorithmic power, but also in regard to lobbying initiatives undermining European law. The technical complexity of internet technology and its global reach were described as further complicating attempts to force transnational technology companies to take European law. Reasoning about Google's non-transparent terms of service and ways of sanctioning by national data protection agencies, the legislator said that locally banning Google would not make any sense since users would learn how to technically circumvent the decision. Moreover, they would not understand the reason and "such a decision would possibly be described as weird by the media" (legislator). Towards the end of the interview, the legislator thus concluded that regulators and governments cannot solve the issue on their own. Acknowledging the limits of classical forms of governance, he called for a joint effort, too:

You don't have to expect much from governments. Rather, the empowerment of the people is significant. In how far they develop critical awareness and stand up for their rights. Or, also, in how far they pressure governments to fight for their rights. Without this pressure there won't be long-term effects. That governments will perfectly protect citizens out of love for fundamental rights is a pure fiction (laughing). This won't happen, since other actors will be too strong.

Again, a joint governance mode that would cut through different areas of society was imagined as being able to meet challenges posed by globally operating search engines like Google and their technical configurations. Since internet technologies were perceived as governing by technical means, it was not only public institutions, but also ordinary citizens and their "mundane activities" (Hofmann et al. 2016: 1415) that were seen as central drivers for making a difference in internet governance. After the "participatory turn" (Cohen 2014) users were not only imagined as participating in corporate surveillance schemes, but also in the shaping and governing of mundane networked technologies they use day by day.

Similar arguments were made by civil society. "Private enforcement" (activist from the law enforcement NGO) was mentioned as being a crucial part of internet governance in practice. The lack of financial resources, however, was described as severely limiting civil society initiatives. Speaking about ways of building up digital literacy in the wider society, an activist said, "Actually, this is a societal duty we take on at our own expense." Comparing civil society activism and industry lobbying, another individual activist added, "this is a fight with unequal weapons". Again, a joint effort was envisioned as a strategy to strengthen local initiatives. Public support of civil society and collaborations between data protection agencies and citizens were particularly mentioned in this respect. Practical problems arising due to the volatile character of Google were described as being harder to solve. Having gone through multiple lawsuits against Silicon Valley companies, the activist from the enforcement NGO characterized internet 
services as slippery objects that are hard to pin down. Talking about practically "opening the server" of these companies, he explained the matter as such: "Imagine you are the data protection agency that has to go through a million, billion terabytes of data: Where do you start? Do you just take out a hard drive and look at it?" Referring to Facebook as a comparative case, he added that even their own engineers would not entirely understand how things work, since they would only program a tiny bit of the whole: "So what do you debate with someone who does not know what is actually running on the machines? (laughing)" Due to practical problems involved in suing private technology companies, privacy-by-design attempts were considered to be more realistic ways of creating technology devoted to local visions and values.

Representatives from the IT sector portrayed local specificities, funding structures and geopolitical ways of thinking as obstacles that prevent the local IT industry from flourishing. Compared to Silicon Valley companies, the "garage myth" is lacking in Austria, as is the "market religion", as the computer scientist put it: "we throw it on the market wall and see what sticks. This is a much stronger, a more essential part of the Silicon Valley approach towards such things compared to our own culture." Moreover, he identified a funding gap between basic and applied research as being responsible for the lack of research on non-commercial technologies serving the public good, like open source projects. Finally, the Google employee raised broader geopolitical concerns. Differentiating between two fundamentally different ways of conceptualizing the internet - as an opportunity or as a threat - the interviewee suggested a joint effort of a very different sort:

I personally hope that in Europe - and I don't only speak of politicians, but also of citizens, entrepreneurs, activists, whatever stakeholders - the focus on opportunities will outweigh the risk debates. (...) If the whole focus is directed at risks, the digital train may pass Europe by, I think.

Contrary to the other interviewees imagining ways of integrating local values into global governance processes, the Google employee basically suggested leaving locality behind and jumping on the global train of technology development. Speaking about historic events, he argued that Austrians still seem to have the "Stasi history" on their minds rather than thinking about all the opportunities of creating innovation with data. In his opinion such fears need to be considered, yet rejecting all opportunities because of them would hurt the economy. Accordingly, he concluded:

If one totally opposes data-driven innovation because of a bizarre mix of antiAmericanism, anti-big business, a general uncertainty (...) due to the NSA affair (...) and if one says "data are bad per se" would be more than reckless because all the possibilities of new technologies are evident.

Narratives about local specificities, both in terms of cultural values and situated 
experiences, have enabled us to see that the rhetoric of both privacy as anti-innovation originating from the US "surveillance-innovation complex" (Cohen 2014) - and privacy as worthy to protect - often considered a genuinely European approach (Mager 2017) can be found on European ground. These opposing viewpoints explain why data protection is such a heated issue in EU legislation. The focus on local perspectives has further opened up a view on the limits of the various governance modes and counterstrategies that may be found in the collective rather than the individual. Joint efforts that go beyond distinct societal arenas and areas of expertise were imagined to challenge globally operating technologies like Google and their governing abilities.

\section{Conclusion}

In this article, I have discussed internet governance in practice. Having investigated the narratives of four distinct actor groups - policy makers, legal experts, civil society, and IT professionals - I have analyzed how different perceptions of Google's "governing by algorithms" were coupled with different suggestions regarding the "governing of algorithms" (Musiani 2013a; Saurwein et al. 2015). Having specifically teased out local perspectives, both regarding the cultural context of Austria and in terms of "situated knowledges" (Haraway 1988), I have further analyzed where the limits of the various governing modes lie and how to overcome them through joint efforts. This analysis strengthens the argument that internet governance is "a proxy for resolving broader global tensions, arising both offline and online" (DeNardis and Musiani 2016: 18). It further shows that the sociotechnical imaginaries of search engines are not only shaped in specific cultural contexts (Mager 2017), but also within particular "communities of practice" (Wenger 1998) and their respective experiences and expertise.

From the perspective of policy makers, Google's governing power was interpreted as a threat to democracy calling for counter-strategies to regain political sovereignty. From legal perspectives, algorithmic forms of governing were seen as an act of lawmaking calling for techniques to force transnational IT companies to take European law. Civil society groups portrayed Google's governing abilities as posing practical problems that should be solved by empowering users and encoding public values in technology. Stakeholders from the IT sector interpreted algorithmic modes of ordering as a technopolitical issue to be met with largely autonomous modes of technologically and economically (re)engineering society. Focusing specifically on local perspectives ultimately enabled us to grasp the limits of the various governing modes that are deeply rooted in cultural specificities, but also in practical dilemmas resulting from the global reach of the technology, its complex configurations, and its volatile character. Having acknowledged the limits of their own governing abilities, representatives from all actor groups called for joint efforts, which cut through different societal arenas, geographical arrangements and areas of expertise. Saurwein et al. (2015: 44, italics in original) similarly suggest "multi-dimensional solutions and combinations of governance measures that mutually enable and complement each other". Inviting practically all stakeholders to 
let go of culturally shaped values - and their legal enforcement - for the sake of global innovation may be considered the most radical proposition in this respect.

This analysis adds to STS-grounded internet governance research by arguing that shifts towards technological forms of governing that are located in corporate internet services and "mundane activities" (Hofmann et al. 2017: 1415) call for joint modes of ordering, drawing together entities from different technological backgrounds, societal fields, and areas of knowledge. To fully exploit their respective potentials, institutional forms of governance may be coupled with technical interventions, governmental modes of ordering complemented with civic engagement, European efforts combined with national initiatives, civil society activism supported by public institutions, private modes of ordering contained by policy frameworks, and technical developments enriched with cultural values. Each of the social groups involved may acknowledge opportunities and limits of their own governance capabilities and reach out to other actors in the heterogeneous network of internet governance, both human and non-human. Joint efforts of this sort can contribute to redistributions of power that challenge central actors like Google and create more diverse search engine landscapes and related services. If civil society actors were strengthened, for example, they would be able to better apply their expertise to regulation, education, and technology development. They would be able to build a stronger lobby for human rights in institutional forms of governance, to empower users by building up digital literacy, and to promote technology developments devoted to local values and the common good. As a consequence, it may be possible to challenge contemporary "power plays in global internet governance" (Carr 2014) and attain a more equal distribution of tasks, responsibilities and resources.

This reordering of power structures may also result in a redistribution of global and local forces. If local stakeholders succeed in making their voices heard in global internet governance, global actors would be increasingly faced with cultural, political and technological barriers. They would have to accept different concepts of privacy that are deeply rooted in historic events, socio-political frameworks and cultural fabrics and they would be required to broaden their own, rather narrow perceptions of privacy as only a matter of anti-innovation. They would have to realize that innovation can take multiple shapes and that value-sensitive design can help to make technology more sustainable in different cultural, economic and political contexts. In sum, they would have to learn how to listen to situated experiences and expertise rather than ignoring locality in order to contribute to more socially robust information technology in the long-run. To reach this goal, all types of actors are invited to express their situated knowledges and to collectively think about ways of unlocking the potential of local know-how. Rather than buying into corporate technology that comes with particular socio-political visions and values, local actors are encouraged to envision, build and govern technology that respects cultural diversity and social needs. If technologies like search engines may be considered basic infrastructure, then processes of technology development and governance should be opened up and democratized. Only when actors from multiple 
corners of the world get the chance to participate in internet governance might it be possible to find joint modes of ordering that go beyond mere regulation and which better correspond to the richness of digital cultures that surround, and co-configure, us.

\section{Funding}

This research was supported by the Austrian Science Fund (FWF); habilitation project "Algorithmic Imaginaries. Visions and values in the shaping of search engines" (20162022; project number V511-G29). The empirical material in this paper was derived from the research project "Glocal search. Search technology at the intersection of global capitalism and local socio-political cultures" (2012-2015; funded by the Jubilee Fund of the Austrian National Bank (OeNB), grant 14702).

\section{Acknowledgments}

I would like to thank my colleagues from the Institute of Technology Assessment (ITA) for their ongoing support. I would further like to thank Florian Saurwein and Helge Torgersen for valuable comments on an earlier version of this paper. Finally, I would like to thank four anonymous reviewers for their encouraging suggestions and Mike Holohan for editing the English.

\section{References}

Badouard R, Mabi C and Sire G (2016) Beyond "Points of Control": logics of digital governmentality. Internet Policy Review 5(3): 1-11.

Barry A (2006) Technological zones. European Journal of Social Theory 9(2): 239-253.

Beer D (2009) Power through the algorithm? Participatory web cultures and the technological unconscious. New Media \& Society 11(6): 985-1002.

Belli L and Venturini J (2016) Private ordering and the rise of terms of service as cyperregulation. Internet Policy Review 5(4): 1-17.

Bogner A and Menz W (2009) The Theory-Generating Expert Interview: Epistemological Interests, Forms of Knowledge, Interaction. In Bogner A, Littig B and Menz W (eds) Interviewing Experts. Hampshire/ New York: Palgrave Macmillan: 43-80.

Boltanski L and Thévenot L (2006) On Justification. Economies of Worth. Princeton, NJ: Princeton University Press.

Carr M (2014) Power Plays in Global Internet Governance. Millennium: Journal of International Studies 43(2): 640-659. 
Cohen JE (2012) Configuring the Networked Citizen. In Sarat A, Douglas L and Umphrey MM (eds) Imagining New Legalities: Privacy and Its Possibilities in the 21 $1^{\text {st }}$ Century. Standford, CA: Standford University Press: 129-53.

Cohen JE (2013) What privacy is for? Harvard Law Review 126: 1904-1933.

Cohen JE (2014) The Surveillance-Innovation Complex: The Irony of the Participatory Turn. In: Barney D, Coleman B, Ross C, et al. (eds) The Participatory Condition in the Digital Age (University of Minnesota Press, 2016). Available at SSRN: https://ssrn.com/abstract=2466708 (accessed January 2018)

Cohen JE (2016) The Regulatory State in the Information Age. Theoretical Inquiries in Law 17: 369-414.

DeNardis L (2009) Protocol Politics. The Globalization of Internet Governance. Cambridge, MA: MIT Press.

DeNardis L (2010) The Privatization of Internet Governance. Fifth Annual Meeting of the Global Internet Governance Academic Network in Vilnius. Lithuania. September 2010.

DeNardis L (2014) The Global War for Internet Governance. New Haven, CT: Yale University Press.

DeNardis L and Musiani F (2016) Governance by Infrastructure. In Musiani F, Cogburn DL, DeNardis L and Levinson NS (eds) The Turn to Infrastructure in Internet Governance. Hampshire/ New York: Palgrave Macmillan: 3-21.

Felt U (2015) Keeping technologies out: Sociotechnical imaginaries and the formation of Austria's technopolitical identity. In Jasanoff S and Kim SH (eds) Dreamscapes of Modernity: Sociotechnical Imaginaries and the Fabrication of Power. Chicago, IL: University of Chicago Press: 103-125.

Foucault M (1982) The Subject and Power. Critical Inquiry 8(4): 777-795.

Fuchs C (2011) A contribution to the critique of the political economy of Google. Fast Capitalism 8(1). Available at: http://www.uta.edu/huma/agger/fastcapitalism/8 1/fuchs8 1.html (consulted December 2017).

Gillespie T (2014) The relevance of algorithms. In Gillespie T, Boczkowski P and Foot K (eds) Media Technologies: Essays on Communication, Materiality, and Society. Cambridge, MA: MIT Press: 167-194. 
Glaser B and Strauss A (1968) The Discovery of Grounded Theory: Strategies for Qualitative Research. London: Weidenfeld \& Nicolson.

Goel S, Broder A, Gabrilovich E and Pang B (2010) Anatomy of the long tail: Ordinary people with extraordinary tastes. Proceedings of the third ACM international conference on Web search and data mining: 201-210. Available at: http://www.wsdmconference.org/2010/proceedings/docs/p201.pdf (consulted December 2017).

Haraway D (1988) Situated Knowledges: The Science Question in Feminism and the Privilege of Partial Perspective. Feminist Studies 14(3): 575-599.

Hardt M and Negri A (2000) Empire. Cambridge, MA: Harvard University Press.

Hofmann J, Katzenbach C and Gollatz K (2017) Between coordination and regulation: Finding the governance in Internet governance. New Media \& Society 19(9): 1406-1423.

Introna L and Nissenbaum H (2000) Shaping the Web: Why the Politics of Search Engines Matters. The Information Society 16(3): 1-17.

Jacobsen J (2016) Suchmaschinenmarktanteile 2016 in Europa. Lunapark Available at: http://www.luna-park.de/blog/9142-suchmaschinen-marktanteile-europa-2014 (consulted September 2017).

Katzenbach C (2013) Media governance and technology. From "code is law" to governance

constellations. In Price ME, Verhulst S and Morgan L (eds) Routledge Handbook of Media Law. New York: Routledge

Lash S (2007) Power after Hegemony: Cultural Studies in Mutation.

Theory, Culture \& Society 24(3): 55-78.

Law J (2008) Actor-Network Theory and Material Semiotics. In Turner BS (ed) The New Blackwell Companion to Social Theory. Oxford: Blackwell: 141 -158

Law J (1994) Organizing Modernity. Cambridge, MA: Blackwell.

Levinson NS and Marzouki M (2015) Internet Governance Institutionalization: Process and Trajectories. In Rioux Mand Fontaine-Skronski K (eds) Global Governance Facing Structural Changes. The Information Technology and Global Governance. Hampshire/ New York: Palgrave Macmillan: 17-35.

Levinson NS and Marzouki M (2016) Global Internet Governance and Development: International Organizations Roles. APSA Annual Meeting, Sep 2016, Philadelphia (PA), United States. 
Lyon D (2002) Everyday Surveillance: Personal data and social classifications. Information, Communication \& Society 5(2): 242-257.

Mager A (2009) Mediated Health. Sociotechnical practices of providing and using online health information. New Media \& Society 11(7): 1123-1142.

Mager A (2012a) Algorithmic ideology: How capitalist society shapes search engines. Information, Communication \& Society 15(5): 769-787.

Mager A (2012b) Search Engines Matter: From educating users towards engaging with online health information practices. Policy \& Internet 4(2): 1-21.

Mager A (2017) Search engine imaginary. Visions and values in the co-production of search technology and Europe. Social Studies of Science 47(2): 240-262.

Marsden CT (2011) Internet Co-Regulation. European Law, Regulatory Governance and Legitimacy in Cyberspace. Cambridge: Cambridge University Press.

Miller CA (2004) Resisting Empire: Globalism, Relocalization, and the Politics of Knowledge. In Jasanoff S and Martello ML (eds) Earthly Politics. Local and Global in Environmental Governance. Cambridge, MA: MIT Press.

Musiani F (2013a) Governance by algorithms. Internet Policy Review 2(3): 1-8.

Musiani F (2013b) Dangerous Liaisons? Governments, companies and Internet governance. Internet Policy Review 2(1): 1-7.

Musiani F (2015) Practice, Plurality, Performativity, and Plumbing Internet Governance Research Meets Science and Technology Studies. Science, Technology \& Human Values 40(2): 272-286.

Pasquinelli M (2009) Google's PageRank Algorithm: A Diagram of the Cognitive Capitalism and the Rentier of the Common Intellect. In Becker K and Stalder F (eds) Deep Search: The Politics of Search Engines Beyond Google. Innsbruck: Studienverlag: 134-152.

Rieder B and Sire G (2014) Conflicts of interest and incentives to bias: A microeconomic critique of Google's tangled position on the Web. New Media \& Society 16(2): 195-211.

Saurwein F, Just N and Latzer M (2015) Governance of algorithms: options and limitations. Digital Policy, Regulation and Governance 17(6): 35-49.

Seale CF (2005) New Directions for Critical Internet Health Studies: Representing Cancer Experience on the Web. Sociology of Health \& Illness 27(4): 515-540. 
Souhrada-Kirchmayer E (2010) Zur Geschichte des Europäischen Datenschutzrechts. In Olechowski T, Neschwara C and Lengauer A (eds) Grundlagen der Österreichischen Rechtskultur. Wien: Böhlau Verlag: 499-518.

Torgersen H (2002) Austria and the transatlantic agricultural biotechnology divide. Science

Communication 24(2): 173-183.

Van Eeten MJG and Mueller M (2012) Where is the governance in Internet governance? New Media \& Society 15(5): 720-736.

Wenger E (1998) Communities of Practice, Learning, Meaning and Identity. Cambridge: Cambridge University Press.

White RW and Horvitz E (2009) Cyberchondria: Studies of the Escalation of Medical Concerns in Web Search. ACM Transactions on Information Systems 27(4), Article No. 23: 1-37.

Wu T (2010) The Master Switch: The Rise and Fall of Information Empires. Random House Digital: 279-280.

Ziewitz M (2016) Governing Algorithms: Myth, Mess, and Methods. Science, Technology \& Human Values 41(1): 3-16.

Ziewitz M and Pentzold C (2014) In search of internet governance: Performing order in digitally networked environments. New Media \& Society 16(2): 306-322.

\section{Author biography}

Astrid Mager is a senior postdoctoral researcher at the Institute of Technology Assessment (ITA), Austrian Academy of Sciences (ÖAW). In addition, she teaches at the Department of Science and Technology Studies, University of Vienna, on a regular basis.

\footnotetext{
i https://www.nytimes.com/2017/02/06/business/trump-travel-ban-apple-google-facebook.html (consulted December 2017) ii https://www.theguardian.com/commentisfree/2017/jan/23/mark-zuckerberg-us-president-facebook-ceo-politics (consulted December 2017)

iii http://www.sciencemag.org/news/2016/10/could-google-influence-presidential-election (consulted December 2017)

iv http://www.ox.ac.uk/news-and-events/oxford-and-brexit/brexit-analysis/views-from-oxford (consulted December 2017)

${ }^{v}$ In this article, the term 'Google' not only refers to Google search, but to the whole variety of services that Google provides, including maps, Email, social network, Analytics, YouTube, etc., as well as the business model that Google employs, and even the company Google (Alphabet Inc.), as they appear to be tightly intertwined in practice (Rieder and Sire 2014).

vi https://en.wikipedia.org/wiki/Twitter Joke Trial (consulted December 2017)

vii https://en.wikipedia.org/wiki/Google Street View in Europe (consulted December 2017)

viii In Austria, consumer protection is organized in the Austrian Chamber of Labor, which is part of the "social partnership" and thus anchored in the political system.

ix Since I have done research on search engine politics before and am thus familiar with the net political scene, it was relatively easy to identify key experts and get field access. Many years of expertise in privacy research of my home institution, the Institute of Technology Assessment in Vienna, additionally helped me with this endeavor. The only problem was time constraints; especially concerning actors operating on the European level.

x http://ec.europa.eu/justice/data-protection/index_en.htm (consulted December 2017)

xi http://ec.europa.eu/justice/data-protection/files/factsheets/factsheet_data_protection_en.pdf (consulted December 2017)

xii All interviews were conducted in German and translated by the author.
} 